\title{
POR UMA GEOGRAFIA ESCOLAR COM AS CRIANÇAS 6869
}

\author{
FOR A SCHOLAR GEOGRAPHY WITH CHILDREN
}

Bruno Muniz Figueiredo Costa ${ }^{7071}$

\begin{abstract}
Resumo
Este texto é um desdobramento de pesquisa de doutorado, em que buscamos compreender, em uma postura dialógica com as crianças, como se dão suas vivências da Geografia Escolar. O contexto de realização da investigação ocorreu em um momento em que havia a ampliação do Ensino Fundamental para nove anos de duração e com a antecipação do ingresso das crianças aos seis anos de idade neste segmento de ensino. Aqui trazemos novos aprofundamentos teóricos por conta de um estágio pósdoutoral que vem sendo realizado, em que as crianças nos revelam como a Geografia Escolar realizada com elas pode ser a possibilidade de alguma garantia de manutenção de suas lógicas infantis frente ao forte processo de escolarização.
\end{abstract}

Palavras-chave: Crianças. Infâncias. Geografia Escolar. Geografia da Infância.

\begin{abstract}
This text is an increases a doctoral research already, in which we seek to understand, in a dialogical posture with children, how their experiences of Schoolar Geography take place. The context of conducting the investigation occurred at a time when there was an expansion of Elementary Education to nine years in duration and with the anticipation of children entering six years of age in this segment of education. Here we bring new theoretical deepening due to a post-doctoral internship that has been carried out, in which children reveal to us how the Schoolar Geography carried out with them may be the possibility of some guarantee of maintaining their children's logic in view of the strong schooling process.
\end{abstract}

Keywords: Children. Childhoods. Schoolar Geography. Childhood Geography.

\footnotetext{
68 Este texto é desdobramento da pesquisa de doutorado Geografia Escolar: Crianças e Infâncias no Primeiro Ano do Ensino Fundamental em Juiz de Fora (MG), vinculada ao Programa de Pós-graduação em Geografia da USP, defendida em 2016, sob orientação da Profa. Dra. Nídia Nacib Pontuschka. A ela a minha gratidão.

${ }^{69}$ A pesquisa contou com verba de fomento do Programa de Apoio à Qualificação (PROQUALI/UFJF) e do CNPQ.

${ }^{70}$ Graduado em Geografia pela Universidade Federal de Juiz de Fora (UFJF), mestre em Educação pela Universidade Federal Fluminense (UFF), doutor em Geografia Humana pela Universidade de São Paulo (USP), realizando estágio pós-doutoral junto ao Programa de Pós-Graduação em Educação da Universidade Federal Fluminense (UFF). Pesquisador associado ao Grupo de Pesquisas e Estudos em Geografia da Infância (GRUPEGI/UFF/UFJF/CNPQ). Professor de Geografia da Educação Básica no Colégio de Aplicação João XXIII/UFJF. Email: brunomunizedu@gmail.com.

71 https://orcid.org/0000-0002-6506-1109
} 


\section{RevistAleph}

O novo não se inventa, descobre-se.

Milton Santos - Por uma Geografia Nova

(2002, p. 18)

Em 1978, Milton Santos introduzia seu mais novo livro - Por Uma Geografia Nova - com esclarecimentos sobre uma eventual impressão que o título trazia acerca de uma pretensa investigação de algo novo. Nessa obra, o professor lançava as bases de uma revisão para a construção de uma Geografia Crítica que abarcasse uma problemática social mais ampla, atendendo à demanda do contexto existente no mundo e, em especial, no Brasil. Eram tempos de instabilidade político-econômica da Guerra Fria e seus reflexos, como o apoio dos EUA ao regime ditatorial brasileiro.

O título do presente texto também se exime de qualquer pretensão maior e revela muito mais um convite para pensarmos o trabalho escolar realizado com as crianças e, em especial, da Geografia Escolar presente nas práticas escolares. Como professor e pesquisador de Geografia da Educação Básica, entendo que nossas práticas docentes são reforçadas pelo lastro histórico e as muitas trajetórias que nos trouxeram até aqui. E a escuta sensível ao que as crianças têm a nos dizer pode nos impulsionar na produção de uma Geografia Escolar a ser realizada com elas e não para elas.

Tomando por base o referencial da Geografia da Infância (LOPES e VASCONCELLOS, 2005; LOPES, 2008 e outros), reconhecemos a impossibilidade de considerarmos as dinâmicas das crianças e suas infâncias fora de suas espacialidades. E compreendemos a necessidade do seu diálogo com a Geografia Escolar.

Assim, para realizar nossa investigação, partilhamos com as crianças matriculadas no primeiro ano do Ensino Fundamental em duas escolas da rede pública de ensino de Juiz de Fora - MG, os momentos das práticas pedagógicas. Dessa maneira, pudemos ouvi-las sobre suas vivências da Geografia que ali se dava.

O que temos, portanto, é um convite ao desafio de pensarmos para além do que o contexto nos apresenta. Contexto esse de ampliação do Ensino Fundamental (EF) para nove anos de duração e da antecipação da idade de ingresso das crianças neste segmento para os seis anos de idade. Situação que impõe sobre as crianças a condição 


\title{
RevistAleph
}

de alunos, com toda a carga que este termo guarda dentro da lógica predominante de escolarização precoce da infância.

\author{
Ou isto ou aquilo \\ Ou se tem chuva e não se tem sol, \\ ou se tem sol e não se tem chuva! \\ Ou se calça a luva e não se põe o anel, \\ ou se põe o anel e não se calça a luva! \\ Quem sobe nos ares não fica no chão, \\ quem fica no chão não sobe nos ares. \\ É uma grande pena que não se possa \\ estar ao mesmo tempo nos dois lugares! \\ Ou guardo o dinheiro e não compro o doce, \\ ou compro o doce e gasto o dinheiro. \\ Ou isto ou aquilo: ou isto ou aquilo... \\ e vivo escolhendo o dia inteiro! \\ Não sei se brinco, não sei se estudo, \\ se saio correndo ou fico tranquilo. \\ Mas não consegui entender ainda \\ qual é melhor: se é isto ou aquilo.
}

Cecília Meirelles (2002, p. 36)

A poesia de Cecília nos instiga a lidar com o viver em uma perspectiva dual que nos causa, por vezes, muito desconforto. Talvez seja porque essa maneira de olhar o mundo guarda consigo uma fixidez do pensamento, desprezando as infinitas possibilidades de existências humanas.

Dentro dessa lógica forjada na Modernidade está a escola, criação dos adultos destinada às crianças, portadora de suas concepções e intencionalidades sobre as infâncias. E por mais que os estudos no campo da Pedagogia tenham alcançado alguns avanços, ainda temos a presença de tais pressupostos, desde a arquitetura escolar às suas práticas cotidianas, ainda fortemente regidas por princípios universalistas e de narrativa única do mundo. Essa constatação nos impele a desnaturalizar o que ocorre no cotidiano escolar e, sobretudo, a buscarmos as intencionalidades presentes nas políticas curriculares que reforçam a ideia do currículo como um instrumento de poder e portador de um projeto de sociedade destinado às próximas gerações. 


\title{
RevistAleph
}

Nessa perspectiva dinâmica de currículo, Silva (2003, p. 15) afirma que, em sua condição cultural, o currículo guarda a seguinte questão: “O que eles devem se tornar? Com essa questão, o autor defende que o currículo, como artefato da cultura, atua na produção de identidades e subjetividades. Dessa forma, configura-se como uma construção social, produzida por diferentes forças que fazem com que "(...) os conflitos em torno da definição do currículo escrito proporcionem uma prova visível, pública e autêntica da luta constante que envolve as aspirações e objetivos da escolarização (GOODSON, 2012, p. 17).

As políticas curriculares são determinadas, em grande medida, na perspectiva de que é possível formar o humano, dar-lhe um molde permanente. A dimensão prescritiva que nossos currículos trazem comporta uma visão focada nas relações cognitivas, que acabam por empobrecedoras, por sufocarem as possibilidades estéticas e de contemplação amorosa. Não dão conta de que a escola é também o espaço do encontro, da alteridade, das vivências, daquilo que jamais será permanente exatamente porque é humano, porque é processual.

\begin{abstract}
A diversidade de valor do existir humano enquanto humano pode apresentar-se somente à contemplação amorosa; somente o amor está em condição de afirmar e consolidar, sem perder e sem desperdiçar, esta diversidade e multiplicidade, sem deixar atrás apenas um esqueleto nu de linhas e momentos de sentido fundamentais. (...). O desamor e a indiferença nunca geram forças suficientes para nos deter e nos demoramos sobre o objeto, de modo que fique fixado e esculpido cada mínimo detalhe e cada particularidade sua (BAKHTIN, 2010, p. 128).
\end{abstract}

Em 2005, a matrícula de crianças no EF aos seis anos de idade tornou-se obrigatória no Brasil, por força de lei ${ }^{72}$. Isso poderia nos levar a imaginar as políticas educacionais brasileiras contextualizando e reconhecendo as crianças em sua concretude. Porém, se tomarmos como base a pouca discussão com a comunidade escolar - em especial, as(os) docentes -, o fato da maioria dos estabelecimentos escolares não estarem organizados estruturalmente para receber esse público e o fato

\footnotetext{
72 BRASIL. Lei $\mathbf{1 1 . 1 1 4}$, de 16 de maio de 2005. Altera os arts. $6^{\circ}, 30^{\circ}, 32^{\circ}$ e $87^{\circ}$ da Lei $n^{\circ} 9394$, de 20 de dezembro de 1996, com o objetivo de tornar obrigatório o início do ensino fundamental aos seis anos de idade. Brasília: [s. n.], 2005.
} 


\section{RevistAleph}

da ampliação do EF para nove anos de duração só ocorrer no ano seguinte ${ }^{73}$, podemos dizer que, no mínimo, trata-se de uma política de improviso. E, neste caso, é de se imaginar que as crianças sequer tenham sido perguntadas sobre essa mudança...

A poesia e as crianças talvez nos ajudem nessa compreensão:

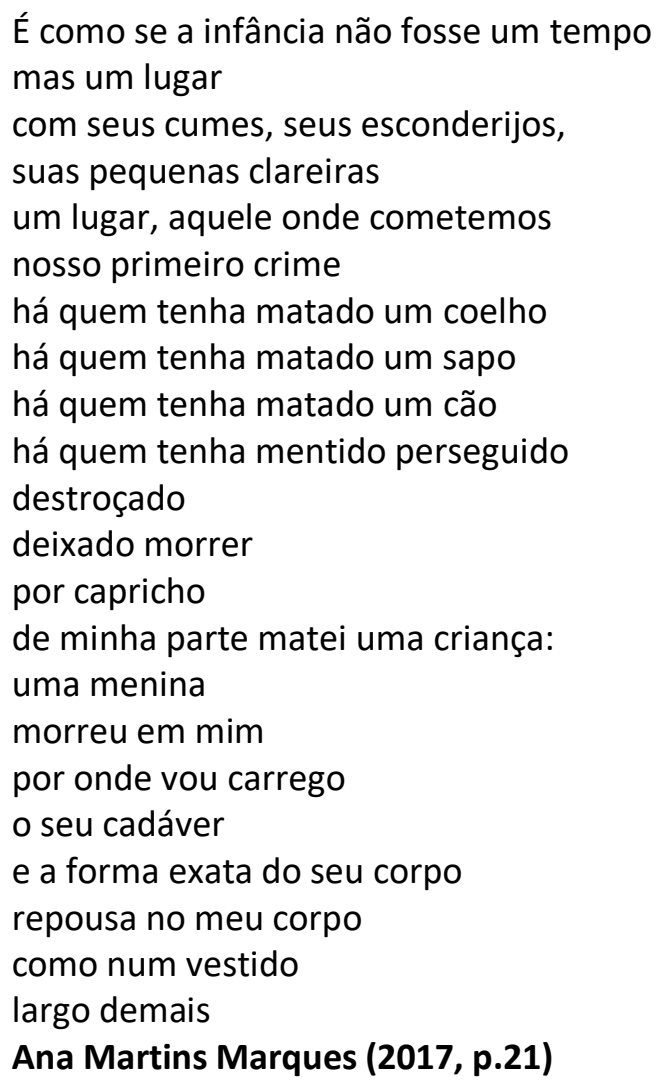

Ângelo concorda com a poetisa:

Ângelo: Tive que comer rápido. Não dá tempo!

Bruno: Não dá tempo de quê?

Ângelo: Do recreio. É que é pouco tempo, então eu me rendo rápido porque aí dá mais tempo pra brincar.

Bruno: Mas por quê?

Ângelo: É que a gente depois tem que voltar para sala. Tem muita coisa pra aprender.

Nota de campo. Ângelo, 6 anos, 2013.

\footnotetext{
73 BRASIL. Lei $11.274,06$ de Fevereiro de 2006. Altera a redação dos arts. $29^{\circ}, 30^{\circ}, 32^{\circ}$ e $87^{\circ}$ da Lei $n^{\circ}$ 9394, de 20 de dezembro de 1996, que estabelece as diretrizes e bases da educação nacional, dispondo sobre a duração de 9 (nove) anos para o ensino fundamental aos seis anos de idade. Brasília: [s. n.], 2006.
} 


\section{RevistAleph}

Não dá tempo...! Uma aceleração que coloca o menino em um comportamento alerta, na busca por garantir uma fundamental atividade da infância: brincar. A criança que há nele é morta aos poucos, como nos afirma a poetisa, pelo antecipado papel adulto de compromissos e tarefas, pela perda do espontâneo em suas vivências escolares.

No campo de estudos da Sociologia da Infância, autores como Qvortrup (2009) defendem que a infância seja uma categoria social geracional permanente na estrutura de qualquer sociedade. Assim, pode ser abordada conjuntamente às demais categorias sociais estruturais, contextualizada histórica, geográfica e culturalmente, sempre integrando a sociedade e a divisão do trabalho. Isso nos possibilita pensar nas crianças também como produtoras da sociedade e de sua infância.

Entre as categorias sociais, a infância é submetida às mesmas forças sociais que os adultos. Contudo, como compõem uma categoria minoritária, as crianças acabam sendo submetidas a ações marginalizadas e paternalizadoras pelo grupo adulto, que as diferencia, especialmente, pelas formas de institucionalização.

Para Qvortrup (2009a), o Estado passa a se apropriar do trabalho das crianças com o advento do processo de industrialização. Isso porque, apesar da infância ser reconhecida tradicionalmente como etapa de proteção, muitas crianças foram levadas de suas famílias para a escola, onde estão menos visíveis como sujeitos sociais que trabalham. E ao afirmar suas atividades escolares como trabalho, o autor ressalta sua invisibilidade nas descrições históricas e sociais.

É importante que se diga da luta das professoras para amenizar essa situação. Contudo, há um movimento do mundo que impõe forças que impactam o currículo escolar decisivamente. É como nos aponta Mello (2012, p. 68-69), ao afirmar a consolidação da escola de EF entre a formação humana e o projeto capitalista, onde

nossas crianças são educadas para “(...) o sério, o economicamente produtivo, o funcional, abandonando gradativamente o brincar e suas possibilidades (...)". Situação vivenciada pelas crianças, que não agem passivamente, mas a ela vão se adequando:

Bruno: Mas o que cês fazem no dia-a-dia? 


\section{RevistAleph}

Paulo: Ah... Todo dia a gente tem que fazer dever depressa, não é Helder?

Helder: Não, nem depressa assim. É por causa que a gente tem horário certo pra gente fazer todos os deveres no caderno.

Paulo: É.

Helder: Pra gente fazer as coisas certas, escrever, a tia copia do quadro, faz isso, faz um título, escreve as histórias.

Paulo: Uhum! E também a gente tem que desenhar as histórias e fazer muitas coisas. Tem que contornar de canetinha, tem que fazer muuuitas coisas.

Helder: O Paulo, mas também a gente tem horário certo pra gente terminar de fazer as coisas e a hora certa da gente começar. Escrever, a de desenhar, a hora de brincar, o horário de ir pra merenda, o horário de ir para o parque, o horário de ir embora, o horário de entrar, sair, tudo tem que ser certo.

Nota de campo. Paulo e Helder, 6 anos, 2013.

É nesse contexto que nossas crianças passam a frequentar um ano a menos na Educação Infantil e obrigatoriamente são introduzidas em uma nova lógica, como alunos de EF. É também dessa maneira que elas passam a tomar contato com a Geografia, como disciplina escolar. Ouvi-las e tentar me aproximar dos significados que atribuíam às suas vivências da Geografia Escolar nessa nova condição me trouxe uma maior compreensão dos impactos dessa nova política em suas vidas.

Ouvir a voz das crianças não se constitui como um simples desiderato metodológico, mas como uma condição decisiva para o estabelecimento do diálogo intergeracional que a ciência social é convidada a realizar

\section{Manuel Sarmento (2007, p. 25).}

A escuta atenta é o que buscamos ao trabalhar em uma perspectiva com as crianças. Ao irmos a campo, buscando os significados que as elas atribuem às vivências da Geografia Escolar no primeiro ano do EF, somos movidos por esse interesse.

As crianças que participaram da investigação nos revelam que as práticas escolares presentes nas escolas são reconhecidas tendo como principal objetivo aprender a ler e a escrever. Seja qual for a proposta, elas procuram identificar aquilo que socialmente lhes é apresentado como principal função: 


\section{RevistAleph}

Bruno: (...). Durante as aulas, durante as aulas o que é que estudam? Que que cês estudam no dia a dia?

Elaine: No dia a dia? É... eu fico aprendendo mais coisas.

Bruno: Mais coisas?

Elaine: É.

Bruno: Que coisas que cê aprende aqui?

Elaine: Aqui? Fazer letra cursiva, ler...

Bruno: Hum... E você, Lúcia?

Lúcia: Eu faço letra cursiva, tento ler...

Nota de campo. Elaine e Lúcia, 6 anos, 2013.

E mesmo nas atividades mais diretamente relacionadas ao saber geográfico escolar, observamos a mesma identificação:

Paulo e Helder, perguntados sobre uma atividade que realizaram sobre as regiões geográficas brasileiras:

Bruno: Entendi. E outro trabalho que eu gostei muito foi o da Região Sul. Cês lembram desse trabalho?

Paulo: Eu lembro.

Bruno: Que que foi legal nesse trabalho?

Paulo: Eu lem... Eu achei legal, que a gente estudou sobre as comidas típicas tipo o angu baiano, feijão tropeiro, arroz carreteiro.

Helder: $\mathrm{E}$ também a gente estudou muito, e muito, e muito, até a gente aprender a ler, mais aí a gente não sabe, a minha mãe...

Paulo: É (incompreensível) não sabe ler por exemplo.

Helder: É, mas a minha mãe tá me ensinando a ler muito tempo. Ela tá fazendo eu ler... três horas (diárias).

Bruno: E esse trabalho da Região Sul ajudou a aprender a ler mais um pouco, a escrever?

Paulo: Ajudou, por causa que... Olha! A gente tava estudando sobre os mapas das regiões, sobre os países, aí ajudou um pouco a gente a aprender a ler.

Helder: É, um pouco. Mas a minha mãe, sabe como é... pra... aprender a ler tem que seguir as palavras, tem que... seguir quase três, duas ou quatro palavras que a minha mãe fala.

Bruno: Entendi.

(...).

Nota de campo. Paulo e Helder, 6 anos, 2013.

O trecho nos mostra como as crianças assumem um discurso de produção da leitura e escrita como finalidade única no primeiro ano do EF. Temos um processo restritivo e um controle excessivo dos usos do espaço escolar e dos tempos que nele se estabelecem, limitando as suas realizações à execução de tarefas e produção de material escrito. Por outro lado, ainda que não reconhecido ou não denominado, o 


\section{RevistAleph}

saber geográfico escolar se faz presente nas práticas que envolvem música, literatura infantil, desenhos, experiência sensorial, Cartografia, Internet e na maneira como as crianças apresentam o mundo às outras. E as crianças vão negociando suas Geografias da Infância com esta Geografia Escolar. É o que nos revela Gabriel:

Ao ser perguntado sobre o que mais gosta de fazer na escola, Gabriel responde:

Gabriel: É também eu gosto de... de escrever, de... (pausa e expiração em sinal de enfado)

Ah, eu gosto é de saber os, enxergar os ônibus de longe né? Porque eu sei.

Bruno: De saber entregar o quê? Os ônibus?

Gabriel: De longe.

Bruno: Daqui você consegue ver os ônibus lá fora?

Gabriel: Ah não! Daqui, daqui dá... algumas vezes de ver de longe, porque quando que eu fico fora da escola, aí eu vejo os ônibus.

(...)

Gabriel: Eu acho que o dia 02 meu pai e minha mãe, a gente vai... vai... ir lá no parque $4^{\circ}$ GAC. Fica... lá em Nova Era (bairro de Juiz de Fora), é longe pra caramba! Então a gente tem que pegar só dois ônibus. Tem que pegar o... os ônibus de São Pedro e ir lá pra cidade, pegar um ônibus azul e ir lá pro $4^{\circ} \mathrm{GAC}$. Pegar de novo o ônibus azul e depois voltar e pegar o (ônibus) 40 . Porque o... (ônibus) 36 , ele não tem... no sábado e no domingo.

Bruno: Humm! E cê sabe isso tudo de ônibus?

Gabriel: É porque... meu avô falou que o 36, ele num passa sábado e domingo. E eu também sei os números dos ônibus, porque o... o Amazonas é..., quer dizer, o Amazonas é 610, o Monte Castelo é 612, 601, 600 e zero, o Jardim Cachoeira é 636 e 601 também, e...

(...).

Nota de Campo. Gabriel, 6 anos, 2013.

São saberes produzidos no cotidiano que nos revelam a dimensão formativa dos lugares produzidos nas vivências de suas Geografias da Infância abrindo possibilidades de simbolização e orientação no espaço geográfico. O garoto tem a cidade sendo desvelada pelos letreiros que os ônibus carregam.

O que podemos perceber nesse processo é uma dimensão dialógica entre a Geografia Escolar e a Geografia da Infância. Trata-se de um movimento em que as crianças vivenciam suas Geografias da Infância e levam-nas ao encontro da Geografia Escolar, ao mesmo tempo em que as práticas escolares Ihes possibilitam revisitar suas Geografias da Infância. 


\section{RevistAleph}

As crianças nos mostraram que, em suas Geografias da Infância, o saber geográfico cotidiano é produzido de muitas maneiras. Em especial, elas destacam sua relação com as tecnologias, tais como GPS, videogame, Internet, televisão, na experiência sensorial, nas brincadeiras, entre outros. Tomam, assim, elementos do mundo vivenciado como suporte para a realização das atividades escolares, negociando as solicitações feitas pela professora e apresentando o mundo aos seus pares.

Nesse movimento, tomam também os elementos da Geografia Escolar e revisitam suas Geografias da Infância, mostrando-nos como a leitura do espaço geográfico é indissociável da leitura da palavra. Além disso, narram sobre os lugares vivenciados e compartilham suas memórias e incluem tais elementos, inclusive, em suas brincadeiras e atividades imaginárias.

Minha mãe achava estudo

A coisa mais fina do mundo.

Não é.

A coisa mais fina do mundo é o sentimento.

Aquele dia de noite, o pai fazendo serão,

Ela falou comigo:

"Coitado, até essa hora no serviço pesado".

Arrumou pão e café, deixou tacho no fogo com água quente.

Não me falou em amor.

Essa palavra de luxo

Adélia Prado (1991, p. 87).

Em qual currículo escolar está contemplado o sentimento? É possível uma política pública curricular para crianças que considere os afetos? São questões que Ângelo nos provoca, ao afirmar o desejo de ser um dono de fábrica:

Bruno: Mas você conhece alguma fábrica? (Ângelo interrompe e pede para escrever em meu caderno de notas: "Ângelo dono de fábrica"). Ângelo: Não, mas eu já passei perto de uma.

Bruno: É mesmo? Onde?

Ângelo: Ah... não sei. Eu fui vender leite com o meu pai e passei perto da fábrica de biscoito. Eu queria conhecer a fábrica.

Nota de campo. Ângelo, 6 anos, 2013. 


\section{RevistAleph}

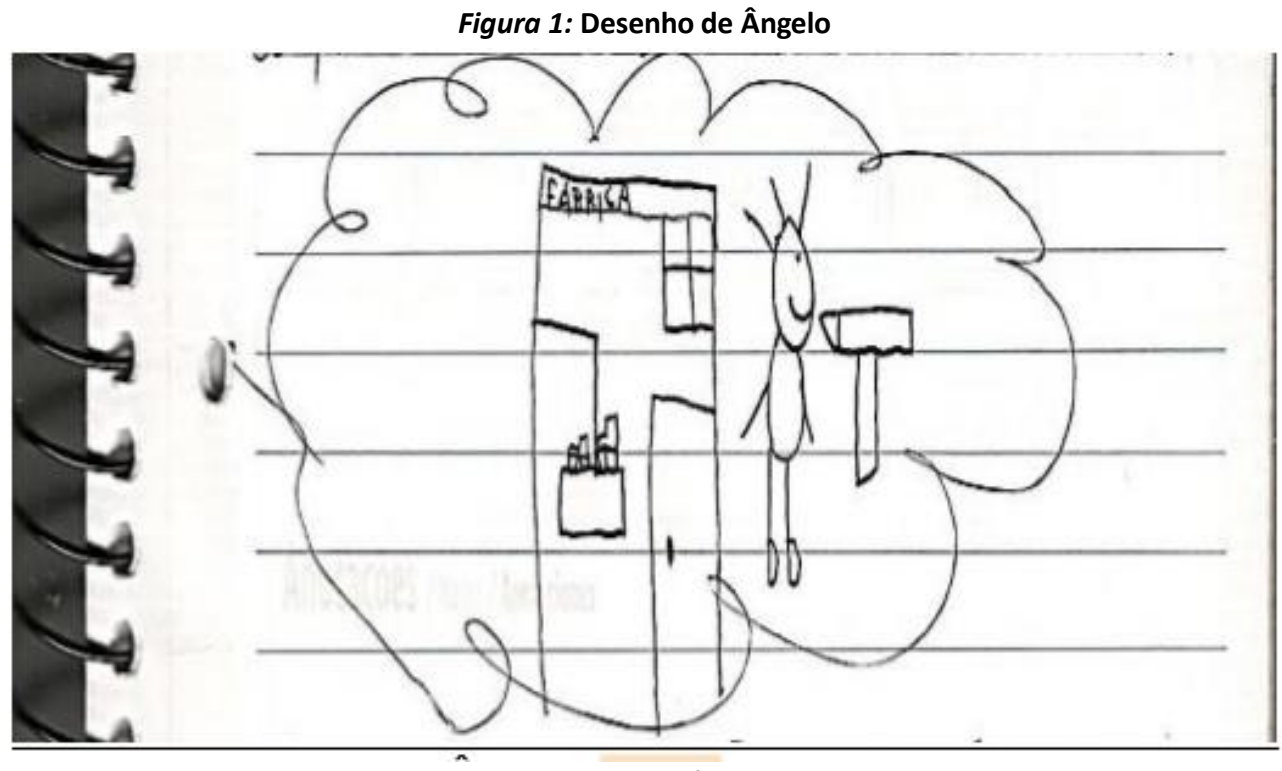

Fonte: Acervo do autor

Segundo o garoto, seu desenho representava uma nuvem de sonhos, onde ele se registrou parado à porta da fábrica. Durante o desenho, ele se remetia a um momento vivenciado com o pai, registrado em sua memória, sobretudo, pela beleza que ele via no prédio e pelo "cheirinho de biscoito" que emanava pelo ar. O que Ângelo nos revela é uma produção de espacialidade em sua Geografia da Infância movida pela intensidade dos afetos e que se faz presente na prática escolar; é apresentada por ele aos demais colegas enquanto toma novos significados, tais como "Eu conheço a fábrica muito bem. É fácil de desenhar".

No início da manhã, na sala de atividades, a professora falava sobre as condições do tempo atmosférico na noite anterior:

Gabriel: Eu vi lá na minha casa.

Professora: É mesmo? Qual lua vocês acham que era ontem?

Helder: Não sei... mas parecia uma banana.

Paulo: Ela vai crescendo até ficar cheia.

(...).

Helder: Eu acho que a lua tá naquela posição... aí ela vai crescendo, crescendo... depois ela vai diminuindo... até virar lua minguante.

Nota de campo. Gabriel, Helder e Paulo, 6 anos, 2013.

O assunto é retomado no dia seguinte: 


\section{RevistAleph}

Paulo: Hoje o tempo está nublado.

Gabriel: Também está com serração... só um pouquinho. É que ontem choveu e depois eu ouvi o relâmpago. Ô tia, no sábado eu via a lua cheia.

Aline: Eu também. Eu vi na sexta e no sábado... tava liiiindaaa! João: Eu gosto de olhar a lua no céu. Aí quando eu chego na aula, eu consigo fazer essa atividade. É molinho...

Paulo: É, mas não tava parecendo uma banana.

Nota de campo. Paulo, Gabriel, Aline e João, 6 anos, 2013.

As notas acima e tantas outras situações nos revelam os enamoramentos das crianças pelos lugares do mundo e os objetos que compõem suas diferentes paisagens. Afetos que se manifestam nas pontas de seus dedos ao percorrerem um planisfério, que permitem percorrer e conhecer "todos os países do mundo inteiro". E dessa forma, parece que "a gente tá viajando", "igual aos navios dos piratas". Nossas crianças revelam a produção de novas espacialidades na escola que envolvem suas lógicas infantis, especialmente nas brincadeiras e atividades imaginárias.

Após uma atividade em que tomaram contato com paisagens da Finlândia durante a primavera, acontece um diálogo entre crianças e professora:

João: Nem dá pra jogar bola... gelo e água, né?

(...)

Ao abordar com as crianças sobre a o longo período de luminosidade dos dias finlandeses nesse período, a professora afirma:

Jussara: O bom é que dá mais tempo pra brincar né? (risos)

João: É bom que eu já descobri um lugar onde eu não quero morar.

Nota de campo. João, 6 anos, 2013.

Essa dimensão afetiva também se dá pelas memórias que trazem dos lugares, que tanto gostam de compartilhar com as demais crianças e com a professora. São narrativas preenchidas pelos cheiros e barulhos dos lugares vivenciados, onde a lua se confunde com uma banana, lugares de baixíssima temperatura não servem para jogar bola e a bandeira que mais importa é a do seu time do coração. Interpretações que estabelecem por suas lógicas próprias de lidar como mundo e suas Geografias.

Durante uma atividade em que as crianças deveriam desenhar um lugar preferido de sua "Coleção de Lugares", Antônio fazia o seu desenho, observado por Fernanda:

Bruno: E o seu (desenho da coleção), Antônio? 


\section{RevistAleph}

Antônio: O cemitério.

Bruno: O seu lugar é o cemitério?

Antônio: É porque... porque meu avô morreu quando eu tinha três anos.

Bruno: Então esse é um lugar que você gosta (expressão de confusão)? Antônio: É, porque tem espaço pra correr.

Bruno: Ah... você corre quando vai lá?

Antônio: Aham.

Bruno: O que mais você faz lá?

Antônio: Eu brinco com meus amigos.

Bruno: Você vai com seus amigos ao cemitério?

Antônio: Vou. A gente brinca de pique-zumbi.

Bruno: E como é que é? Me conta?

Antônio: Oh... é tipo pique-pega, oh... Tá com uma pessoa, aí a pessoa pega e as duas pessoas viram zumbi.

Bruno: Ah... entendi.

Depois da realização das atividades, procuro as crianças e comento:

Bruno: Gostei do cemitério na sua coleção de lugares preferidos.

Fernanda: É... mas não é verdade.

Antônio: Claro né? É na nossa imaginação. A gente fala que vai nele na nossa imaginação. É maneiro!

Nota de Campo. Antônio e Fernanda, 6 anos, 2013.

Figura 2: Desenho de Antônio

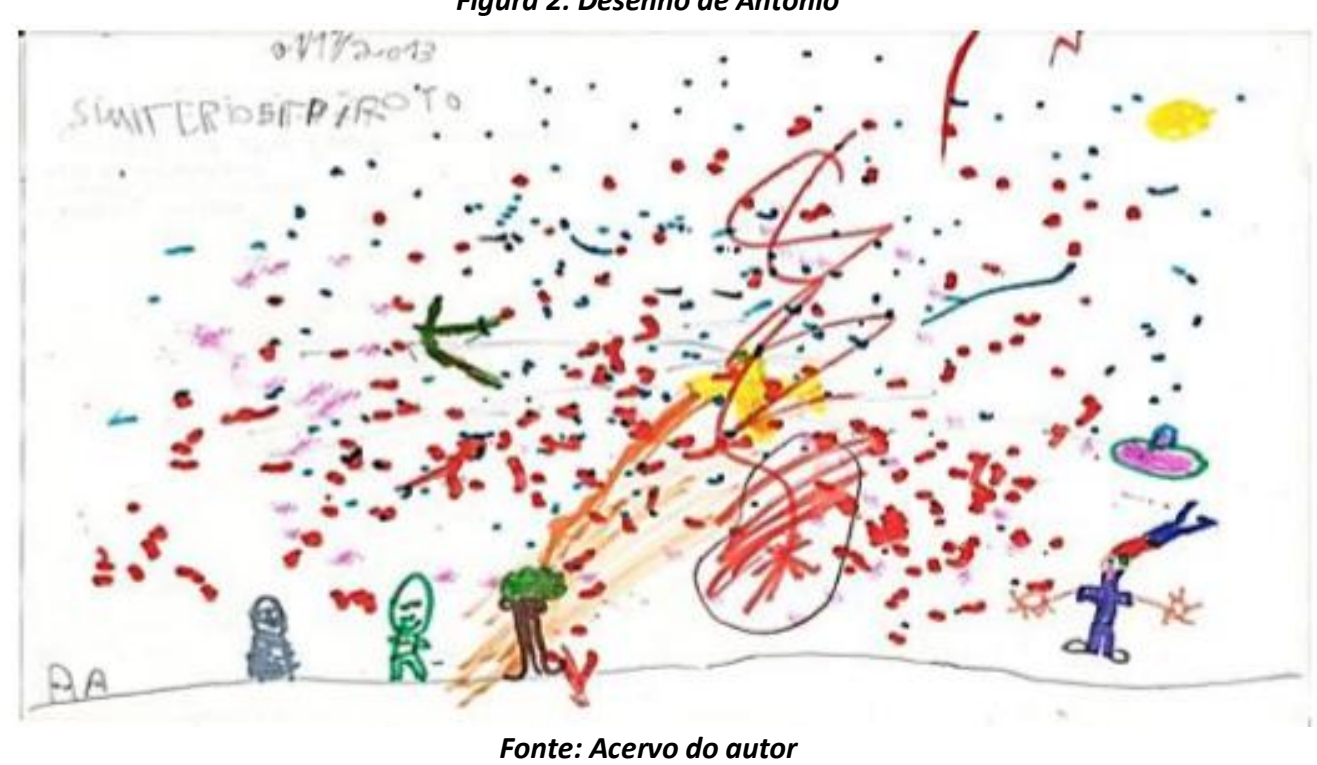

ISSN 1807-6211 [Dezembro. 2020] № 35 


\section{RevistAleph}

Ainda que exista a saudade pela perda do avô, o mesmo lugar é suporte para imaginar brincadeiras e o inusitado. É uma “imaginação criadora” (VIGOTSKI, 2009), lastreada histórica e geograficamente, onde a criança acha pausas para a contemplação de si, do outro e do mundo. As crianças conseguem ir além de si, quando brincam e produzem novas espacialidades, quando "A gente fala dele na nossa imaginação", o que faz a Geografia Escolar ser algo que "É maneiro!", por abrir-se à experiência da fruição, do estético.

Tradicionalmente, as interpretações e adaptações da perspectiva piagetiana para o trabalho da Geografia Escolar nos anos iniciais do EF, defendiam que o ponto de partida deveria ser o imediato da criança, ou seja, sua casa, depois a rua, depois o bairro, a cidade, sucessivamente. Porém, o que as crianças nos mostraram é que concebem um evento espacial em unidade e não em partes hierarquizadas. Nesse sentido, o ponto de partida só deveria ser importante quando estabelecido pela própria criança, por seu repertório de vivências e que comporta suas diversas formas de expressão.

Ao transitarem entre o real e o imaginário, narrando suas vivências nos diferentes lugares, as crianças nos mostram o quanto a construção de sua noção espacial está atrelada às suas vivências e intensidades. É um convite, inclusive, a tencionarmos a perspectiva de trabalho em círculos escalares concêntricos, ainda tão presentes nas práticas escolares que envolvem o espaço. As crianças nos apresentam uma espacialidade que não se constitui de forma linear e por etapas, mas de forma processual e revolucionária.

Com a colaboração das crianças, defendemos uma Geografia Escolar com crianças como um campo de saberes autônomo, produzido no cotidiano da escola, na interface entre a dimensão formativa dos lugares pelos sujeitos, as orientações oficiais, as bases teóricas acadêmicas, além de outras instâncias, como as diferentes mídias, os livros didáticos, a literatura, as artes, a brincadeira, entre outras. É um campo composto pelos discursos dos diferentes sujeitos que o constituem, de forma contextualizada. 


\section{RevistAleph}

Revela, assim, a necessidade de a escola abarcar os sujeitos em sua totalidade, o que inclui a sua condição de sujeitos geográficos.

Tradicionalmente, o saber geográfico vem sendo tratado como algo menos importante pela escola. Isso passa pelas políticas curriculares, pela formação de professores e de avaliação da educação, que privilegiam a apropriação do saber ler, escrever e calcular, em detrimento de outras possibilidades. E o argumento em favor do protagonismo infantil, inclusive, vem sendo apropriado para alimentar o acirramento das disputas em torno da infância, que não são descoladas da lógica de produção vigente.

O que está em jogo é a consideração da condição social ativa das crianças. E como tais, são também produtoras de Geografias, em suas lógicas próprias, que também comportam atitudes de comparação, análise, associação, relação, organização das formas e funções das paisagens, localizações e dinâmicas, semelhanças e diferenças, entre outras. Por outro lado, a defesa de uma Geografia Escolar com crianças é incompatível com um tratamento disciplinar que se pretende sistematizador da complexidade do mundo, sob o sapiente olhar adulto, porque essa é uma demanda adulta. Se a Geografia Escolar não considera essa possibilidade, desperdiça uma valiosa episteme.

As crianças nos levam à defesa de uma Geografia Escolar na qual nadar nos "pocinhos" formados pela cachoeira, descer escadas, perseguir os quatis que habitam a mata vizinha à escola, encontrar um grilo ou um formigueiro pelo caminho, comer "pauzinho-doce", retomar a memória dos cheiros, barulhos, brincadeiras, movimentos e demais aspectos do espaço geográfico vivenciado, é tão importante quanto qualquer outro saber. Uma Geografia não-didatizada, com crianças que são as principais responsáveis pela manutenção da Geografia Escolar na escola...

Trata-se de uma atitude no mundo que busca com elas aprender... não se trata de subordinação aos seus desejos, mas de uma escuta que confia em suas vozes. Geografia Escolar em que é permitido criancear. Como nos diz o poeta:

A infância não é um tempo, não é uma idade, uma coleção de memórias.

A infância é quando ainda não é demasiado tarde.

É quando estamos disponíveis para nos surpreendermos, 


\section{RevistAleph}

para nos deixarmos encantar

Mia Couto (2011, p. 55).

\section{Referências}

BAKHTIN, M. Para uma filosofia do ato responsável. São Carlos: Pedro \& João Editores, 2010.

COUTO, Mia. E se Obama fosse africano?: e outras intervenções. São Paulo: Companhia das Letras, 2011.

GOODSON, I. Currículo: teoria e história. 12 ed. Petrópolis: Vozes, 2012.

LOPES, J. J. M. A criança e sua condição geográfica: contribuições de Geografia da Infância. 0 Social em Questão. Puc-Rio: Rio de Janeiro, 2008. p. 109-122.

LOPES, J. J. M. VASCONCELLOS, T. Geografia da Infância: reflexões sobre uma área de pesquisas e estudos. Juiz de Fora: FEME, 2005.

MARQUES, A. M. É como se a infância não fosse um tempo... In: FENATI, M. C. (org.) Infância. Belo Horizonte: Chão de Feira, 2017, p. 21.

MEIRELES, C. Ou isto ou aquilo. Ilustrações de Thais Linhares. 6. ed. Rio de Janeiro: Nova Fronteira, 2002.

MELLO, M. B. de. Autorias infantis: pelo direito às infâncias na escola do Ensino Fundamental. In: ANDRADE, D. B. da S. F.; LOPES, J. J. M. (Orgs.). Infâncias e crianças: lugares em diálogos. Cuiabá: EdUFMT, 2012. p. 63-74.

PRADO, A. Poesia reunida. São Paulo: Siciliano, 1991.

QVORTRUP, J. Childhood as a Structural Form. In: QVORTRUP, J.; CORSARO, W. A.; HONIG, MS. The Palgrave Handbook of Childhood Studies. London: Palgrave Macmillan, 2009. Cap. 1, p. 21-33.

QVORTRUP, J. The development of childhood: change and continuity in generational relations. In: QVORTRUP, J.; CORSARO, W. A.; HONIG, M-S. Structural, historical and comparative perspectives. London: Emerald Books, 2009a. Cap. 1, p. 1-25.

SANTOS, Milton. Por uma Geografia Nova. São Paulo: EdUSP, 2002.

SARMENTO, M. J. Visibilidade social e estudo da infância. In: VASCONCELLOS, V. M. R. de.; SARMENTO, M. J. Infância (in)visível. Araraquara: Junqueira \& Martim, 2007. p. 25-49.

SILVA, T. T. da. Documentos de identidade. 2 ed. Belo Horizonte: Autêntica, 2003.

VIGOTSKI, L. S. Imaginação e criação na infância. São Paulo: Ática, 2009.

Data do envio: $07 / 07 / 2020$

Data do aceite: $04 / 11 / 2020$ 